\title{
The effect of Prolactin in response to academic stress during examination condition in healthy male and female University students
}

\author{
Bako Ibrahim Gaya ${ }^{1, ~ *, ~ M a b r o u k ~ M o h a m e d ~ A b d e l-a z e e z ~}{ }^{2}$, Abubakar Muhammad Sani ${ }^{3}$, \\ Salihu Khadijat Haladu ${ }^{1}$, Malgwi Samaila Ibrahim ${ }^{1}$ \\ ${ }^{1}$ Department of Human Physiology, Faculty of Medicine, Ahmadu Bello University Zaria, Nigeria \\ ${ }^{2}$ Department of Medical Physiology, Faculty of Medicine, Al- Azhar University Cairo, Egypt \\ ${ }^{3}$ Ahmadu Bello University Health Services Sick Bay, Samaru - Zaria, Nigeria
}

\section{Email address:}

gibako@abu.edu.ng(B. I. Gaya)

\section{To cite this article:}

Bako Ibrahim Gaya, Mabrouk Mohamed Abdel-azeez, Abubakar Muhammad Sani, Salihu Khadijat Haladu, Malgwi Samaila Ibrahim. The Effect of Prolactin in Response to Academic Stress during Examination Condition in Healthy Male and Female University Students. American Journal of BioScience. Vol. 2, No. 1, 2014, pp. 1-4. doi: 10.11648/j.ajbio.20140201.11

\begin{abstract}
The effect of Prolactin in response to academic stress was studied in forty healthy male and female University students during their final year seminar presentation examination. The data collected are some Anthropometric parameters, Blood pressure (diastolic and systolic) and prolactin level. The arterial blood pressure was measured by auscultatory method using stethoscope and sphygmomanometer. Serum prolactin level in blood sample collected from each subject was analyzed using prolactin ELISA kit. The serum prolactin level in students under examination condition when compared to students not under examination increased significantly $(\mathrm{P}<0.05)$. The blood pressure also increased with a significant statistical value $(\mathrm{P}<0.05)$ when the test group was compared to the control group. It can therefore be inferred that Prolactin level increases in academic stress in both male and female may be a useful neuro-endocrine link to stress.
\end{abstract}

Keywords: Prolactin, Academic, Stress, Examination, Systolic, Diastolic, Pressure, Student

\section{Introduction}

Academic stress has carried a lot of attention that is why its consequences attract research at all levels in the academic circle. In the academic institutions, stress has been categorized to have both positive and negative consequences if not managed well [6]. Despite the increase in technological development and the rapid growth of information, competition among all group of people has become on the increase, as a result people become more occupied and tensed up with stress [1-2]. Although appropriate stress is a stage for self-growth and it gives people motivation for advancement in life. Nevertheless, overstress causes problems and discomfort which can have a serious consequences on people. Academic pressure is a significant source of stress for many University students [16]. A very good number of identified sources of academic-related stress have included fear of not passing coursework, time pressures, financial worries, and concern about academic ability [17]. Additionally, students report stress over struggling to meet academic standards, time management worries, and concerns over grades. Prolactin is a polypeptide hormone synthesized and secreted by the lactotrophs [26]. Indeed, not only does prolactin sub-serve multiple roles in reproduction other than lactation, but it also plays multiple homeostatic roles in the organism by regulation of the immune system, [10] osmotic balance, [12] and angiogenesis [7]. Furthermore, we are now aware that synthesis and secretion of prolactin [23] is not restricted to the anterior pituitary gland, [9] but other organs and tissues in the body have this capability $[11,13]$. This study is intended to evaluate the effect of prolactin hormone in response to stressful events in the life of University students. The students are required to earn a minimum of one hundred and twenty credit units before graduation as Bachelor Science Degree (B.Sc). 


\section{Materials and Methodology}

\subsection{Materials}

The following materials were used for the research work; 40 Standard bottles, $2 \mathrm{ml}$ pipette, Bench Centrifuge Hawksley RegNo891481 Ser. No. 07.4.26, Weighing balance H80 Gallenhamp, Biorad-machine Registration number 5100, Sphygmomanometer and stethoscope, Cotton wool and disinfectant (methylated spirit), Subjects 40 healthy male and female final year B.Sc. Human Physiology students.

\subsection{Data Collection}

The study was compiled with the ethical committee guidelines of Ahmadu Bello University Teaching Hospital, Zaria. The procedures followed were in accord with the ethical standards of Ahmadu Bello University, Zaria, with registration number $\mathrm{ABUTH} / \mathrm{PGO} / \mathrm{COMM} / 0038$. The data of forty healthy male and female final year students in the Department of Human Physiology, Faculty of Medicine, Ahmadu Bello University Zaria, Nigeria. The consent of all participants was sorted through questionnaire and the participants had a good medical history with an exclusion criterion of smokers, lung diseases, endocrine disorders and cardiovascular diseases. The test group was subjected to an examination condition of seminar presentation of literature review by each final year student which last for ten minutes before a panel of examiners. The data of these students in this group are then immediately collected after the seminar presentation. The control groups are students whose data were collected at the beginning of the semester after coming back from semester break. The subjects were categorized into twenty male and female students not under examination condition and twenty male and female students under examination condition. The students were further grouped into Control (ten male and ten female) and test group (ten male and ten female). The data collected from all the subjects with an age range of 23-30 years by random sampling are; age (years), weight $(\mathrm{kg})$, blood pressure (mmHg), blood sample in September, 2011.

\subsection{Climate of the Research Area}

The research was carried out in Zaria with the following climatic conditions: mean annual rainfall $1000 \mathrm{~mm}$, mean annual temperature $27^{\circ} \mathrm{C}$, longitude and latitude $11^{\circ} 3^{\prime} \mathrm{N}$, $7^{\circ} 42^{\prime} \mathrm{E}$, height $670 \mathrm{~m}$ above sea level and $664 \mathrm{~km}$ away from the sea, with a dry and wet season [19].

\subsection{Prolactin Analysis}

Blood sample were collected from the subjects and immediately centrifuged to obtain serum for the determination of prolactin. The analysis was conducted in the Department of Chemical Pathology Ahmadu Bello University Teaching Hospital, Shika-Zaria. The prolactin enzyme-linked immunosorbent assay (ELISA) kit
FORTRESS DIAGNOSTICS ${ }^{\circledR}$ Limited, BXE0671A UK in microplate was designed for the quantitative evaluation of prolactin. The microplate is coated with a first monoclonal antibody prolactin. Calibrators and samples are pipetted into the antibody coated microplate. During 2 hours incubation endogenous prolactin in the sample bind to the antibodies fixed on the inner surface of the wells. Nonreactive sample components are removed by a washing step. Afterwards, a second polyclonal horseradish peroxidase-labeled antibody, directed against another epitope of the prolactin molecule, was added. During 1 hour incubation, a sandwich complex consisting of the two antibodies and the prolactin is formed. An excess of enzyme conjugate was washed out. A chromogenic substrate, TMB (3,3',5,5'-Tetra-Methyl-Benzidine), was added to all the wells. During 30 minutes incubation, the substrate was converted to a colored end product (blue) by the fixed enzyme. Enzyme reaction was stopped by dispensing of hydrochloric acid as stop solution. The color intensity is direct proportional to the concentration of prolactin present in the sample. The optical density of the color solution is measured with a microplate reader at 450 nm. A standard curve was obtained by plotting the concentration of the standard versus the absorbance. The PRL concentration of the specimens and controls run concurrently with standards were calculated from standard curve. The lowest detectable level of prolactin [8] with this test was $0.8 \mathrm{ng} / \mathrm{mL}$.

\subsection{Data Analysis}

All data are expressed as mean \pm standard of error mean (Mean \pm S.E.M.).The data obtained were analyzed using ttest student-Newman Keul's test, SPSS package version 20.0 and post hoc test for multiple comparisons. The $(\mathrm{P}<0.05)$ was accepted as significant.

\section{Results and Discussion}

Table 1. Students grouped into non examination condition and examination condition

\begin{tabular}{lcccc}
\hline \multicolumn{1}{c}{ Parameters } & $\begin{array}{c}\text { Body } \\
\text { Weights } \\
\mathbf{( K g )}\end{array}$ & $\begin{array}{c}\text { Systolic } \\
\text { BP } \\
(\mathbf{m m H g})\end{array}$ & $\begin{array}{c}\text { Diastolic } \\
\text { BP } \\
(\mathbf{m m H g})\end{array}$ & $\begin{array}{c}\text { Prolactin } \\
\text { Level } \\
(\mathbf{n g} / \mathbf{m l})\end{array}$ \\
\hline Students grouping & & & & \\
Non exam condition & $58.6 \pm 2.5$ & $114 \pm 2.2$ & $65 \pm 1.4$ & $14.21 \pm 0.4$ \\
Exam condition & $56.6 \pm 3.2^{\mathrm{NS}}$ & $118 \pm 1.9^{\mathrm{S}}$ & $78 \pm 3.1^{\mathrm{S}}$ & $17.73 \pm 0.5^{\mathrm{S}}$ \\
\hline
\end{tabular}

Not significant $=$ NS; Significant $=\mathrm{S}(\mathrm{P}<0.05)$

Table 2. Students grouped into sub-groups of male and female control and test groups

\begin{tabular}{lcc}
\hline \multirow{1}{*}{ Parameters } & \multicolumn{2}{c}{ Prolactin Level (ng/ml) } \\
\cline { 2 - 3 } & Male students & Female students \\
\hline Students grouping & & \\
Non exam condition & $14.09 \pm 0.7$ & $14.32 \pm 0.4$ \\
Exam condition & $16.97 \pm 0.9^{\mathrm{S}}$ & $18.50 \pm 0.5^{\mathrm{S}}$ \\
\hline
\end{tabular}

Significant $=\mathrm{S}(\mathrm{P}<0.05)$ 
The results of students grouped into non examination condition and examination condition are shown in table 1. The blood pressure (diastolic and systolic) of the students under examination condition increased significantly $(\mathrm{P}<0.05)$ when compared to the students not under examination condition. Prolactin level of students under examination condition increased significantly $(\mathrm{P}<0.05)$ when compared to students not under examination. In the sub-groupings, prolactin in male students under examination condition increased significantly $(\mathrm{P}<0.05)$ when compared to male students not under examination. Also in female sub-groupings, prolactin in female students under examination condition increased significantly $(\mathrm{P}<0.05)$ when compared to female students not under examination as shown in table 2 .

\section{Prolactin Response to Academic Stress}

The result of the present study showed that the prolactin level of students under examination when compared to the prolactin level of students that are not under examination condition increased significantly. This shows that academic stress may likely be one of the stressors responsible for the increase of prolactin level. Stressful conditions may usually lead to changes in serum level of many hormones [25]. There is evidence that stress influences prolactin secretion in animals and humans [20]. However various situations and laboratory stressors can induce a significant increase in prolactin secretion [18]. The multiple roles and sources of prolactin may give the hormone the versatile function on many biological actions in which its secretion in response to stress could be one $[12,24]$. Although, over years we know that prolactin have numerous separate biological actions. Indeed, not only does prolactin sub-serve multiple roles in reproduction other than lactation, but it also plays numerous homeostatic roles in the organism [4]. Furthermore, we are now aware that synthesis and secretion of prolactin is not restricted to the anterior pituitary gland, but other organs and tissues in the body have this capability. When an animal or human is exposed to any enormous variety of deleterious or potentially lethal stimuli, there is an increased secretion of ACTH, which as a result, leads to rise in the circulating glucocorticoid level [14]. Although, the rationale of an elevated circulating glucocorticoid level is essential for resisting stress remains for the most part unknown. Academic pressure is a significant source of stress for many college students [16]. Identified sources of academic-related stress have included fear of falling behind with coursework, finding the motivation to study, time pressures, financial worries, and concern about academic ability [28]. Additionally, students report stress over struggling to meet academic standards, time management worries, and concerns over grades [22]. These sources may exist easily throughout the span of college students' academic careers and may result in college students' experiencing a great deal of stress during their college career [21]. The fact that certain individuals might not habituate to chronic psychogenic stressful stimuli, their behavioral responses $[5,27]$ to stress may lead them to different neuro-endocrine [3] responses. This might explain the individual differences observed in the impact of stress on physical and psychological well-being. Prolactin could become an essential tool in studying the physio-pathologic [14] implications of certain behavioral patterns because of its versatile biological roles and also a valuable neuroendocrine [15] connection of the individual response to stress.

\section{Conclusion}

Academic stress may likely be one of the stressors responsible for the increase of prolactin level. Prolactin could become an essential tool in studying the physiopathologic implications of certain behavioral patterns because of its versatile biological roles and also a valuable neuro-endocrine connection of the individual response to stress.

\section{Acknowledgement}

We acknowledge the contributions of technical staff from Department of Human Physiology Mallam Bala Mohammed and Nura Mohammed; and $\mathrm{Mr}$ Felix Oluwatudimu Ayegbusi from the Department of chemical Pathology Ahmadu Bello University Teaching Hospital Shika-Zaria, Nigeria.

\section{References}

[1] Agolla JE, Occupational Stress among Police Officers. The case of Botswana Police service, Res. J. Bus. Management, 2009; 2(1): 25-35.

[2] Angelier F, Moe B, Blanc S, and Chastel O, What factors drive prolactin and corticosterone responses to stress in a long-lived bird species (snow petrel Pagodroma nivea)? Physiological Biochem. Zoology, 2009; 85(5): 590-602.

[3] Ali S, Pellegrini I, and Kelly PA, A prolactin-dependent immune cell line (Nb2) expresses a mutant form of prolactin receptor. J Biol Chem 1991; 266: 20110-20117.

[4] Bole-Feysot C, Goffin V, Edery M, Binart N, and Kelly PA, Prolactin (PRL) and its receptor: actions, signal transduction pathways and phenotypes observed in PRL receptor knockout mice. Endocr Rev. 1998; 19: 225-268.

[5] Bridges RS, Prolactin stimulation of maternal behavior in female rats. Science 1985; 227: 782-784.

[6] Chang K, and Lu L, Characteristics of organisational culture, stressors and wellbeing: The case of Taiwanese organisations, J. Manage. Psychol. 2007; 22 (6): 549-568.

[7] Clapp C, and De la Escalera GM, Prolactins: novel regulators of angiogenesis. News Physiol Sci. 1997; 12: 231-237. 
[8] Dombrwicz D, Sente B, Closset J, and Hennen G, Dosedependent effects of human prolactin on immature hypox rats testis. Endocrinology, 1992; 130: 695-700.

[9] Dutt A, Kaplitt MG, Kow LM, and Pfaff DW, Prolactin, central nervous system and behavior: a critical review. Neuroendocrinology, 1994; 59: 413-419.

[10] Freeman ME, Kanyicska B, Lerant A, and Nagy G, Prolactin: structure, function, and regulation of secretion. Physiol Rev, 2000; 80:1523-1631.

[11] Gala RR, and Shevach EM, Evidence for the release of a prolactin-like substance by mouse lymphocytes and macrophages. Proc Soc Exp Biol Med 1994; 205:12-9

[12] Ganong WF, Review of medical physiology. Twenty fourth edition, Lange publication, USA, 2007: pp. 444-550.

[13] Goffin V, Bouchard B, Ormandy CJ, Weimann E, Ferrag F, Touraine P, Bole-Feysot C, Maaskant RA, Clement-Lacroix P, Edery M, Binart N, and Kelly PA, Prolactin: a hormone at the crossroads of neuro-immuno-endocrinology. Ann NY Acad Sci. 1998; 840: 498-509.

[14] Guyton AC, and Hall JE, Textbook of medical physiology. Eleventh Edition, Elsevier, 2006: pp. 950-1050.

[15] Hadley ME, Endocrinology, third edition, Englewood Cliffs: Prentice-Hall, 1992: pp-98-123.

[16] Hashim IH, Cultural and gender differences in perceptions of stressors and coping skills: A study of Western and African college students in China. School Psychology Inter. $2003 ; 24: 182-203$.

[17] Lennartsson AK, and Jonsdottir IH, Prolactin in response to acute psychosocial stress in healthy men and women. Psycho-neuro-endocrinology, 2011; 36(10):1530-9.

[18] Malarkey WB, Hall JC, Pearl DK, Kiecolt-Glaser JK, and
Glaser R, The influence of academic stress and season on 24-h concentrations of growth hormone and prolactin. J Clin Endocrinol Metab. 1991; 73: 1089-1092.

[19] Marthins MI, Zaria and its region. Department of Geography Ahmadu Bello University, Zaria, 2006: pp-41.

[20] Maurizio F, and Gian PG, Prolactin and stress. S. Med. 2006; 3:211-216

[21] Olivier C, Andre L, Henri W, and Gier WG, Modulation of prolactin but not corticosterone responses to stress in relation to parental effort in a long-lived bird. Hormones and behavior, 2005; 47:459-466.

[22] Olpin MN, Perceived stress levels and sources of stress among college students: Methods, frequency, and effectiveness, NASPA Journal, 1997; 44:3 pp-429.

[23] Owerbach D, Rutter WJ, Cooke NE, Martial JA, and Shows TB, The prolactin gene is located on chromosome 6 in humans. Science 1981; 212: 815-816.

[24] Paul G, Human endocrinology, T.J. international, first edition, Padstow, UK, 2001: pp-20-31.

[25] Ranabir S, and Reetu K, Stress and hormones. Indian Journal of Endocrinology and metabolism, 2011;15(1):1822.

[26] Riddle O, Bates RW, and Dykshorn SW, The preparation, identification and assay of prolactin a hormone of anterior pituitary. Am J Physiol. 1933; 105: 191-216.

[27] Sobrinho LG, Prolactin, psychological stress and environment in human: adaptation and maladaptation. Pituitary, 2003; 6(1):35-9.

[28] Tyrrell J, Sources of stress among psychology undergraduates. Irish Journal of Psychology, 1992; $13: 184.192$. 